\title{
Rapid evolution of a native species following invasion by a congener
}

\section{Citation}

Stuart, Y. E., T. S. Campbell, P. A. Hohenlohe, R. G. Reynolds, L. J. Revell, and J. B. Losos. 2014. "Rapid Evolution of a Native Species Following Invasion by a Congener." Science 346 (6208) (October 23): 463-466. doi:10.1126/science.1257008.

\section{Published Version}

10.1126/science. 1257008

\section{Permanent link}

http://nrs.harvard.edu/urn-3:HUL.InstRepos:22907490

\section{Terms of Use}

This article was downloaded from Harvard University's DASH repository, and is made available under the terms and conditions applicable to Open Access Policy Articles, as set forth at http:// nrs.harvard.edu/urn-3:HUL.InstRepos:dash.current.terms-of-use\#OAP

\section{Share Your Story}

The Harvard community has made this article openly available.

Please share how this access benefits you. Submit a story.

Accessibility 


\section{Title: Rapid evolution of a native species following invasion by a congener}

2 Authors: Y.E. Stuart ${ }^{1 *}{ }^{\star}$, T.S. Campbell ${ }^{2 \wedge}$, P.A. Hohenlohe ${ }^{3}$, R.G. Reynolds ${ }^{1,4}$, L.J. Revell ${ }^{4}$, and

3 J.B. $\operatorname{Losos}^{1}$

4 Affiliations:

$5{ }^{1}$ Museum of Comparative Zoology and Department of Organismic and Evolutionary Biology,

6 Harvard University, Cambridge, MA.

$7 \quad{ }^{2}$ Department of Biology, University of Tampa, Tampa, FL.

$8{ }^{3}$ Department of Biological Sciences and Institute for Bioinformatics and Evolutionary Studies,

9 University of Idaho, Moscow, ID.

$10{ }^{4}$ Department of Biology, University of Massachusetts, Boston, MA.

$11{ }^{\wedge}$ Co-first authors

$12 *$ Correspondence: yestuart@utexas.edu

13 † Current Address: Department of Integrative Biology, University of Texas, Austin, TX.

15 Abstract: In recent years, biologists have increasingly recognized that evolutionary change can

16 occur rapidly when natural selection is strong; thus, real time studies of evolution can be used to

17 test classic evolutionary hypotheses directly. One such hypothesis, that negative interactions

18 between closely related species can drive phenotypic divergence, is thought to be ubiquitous

19 though well-documented cases are surprisingly rare. On small islands in Florida, we found that

20 the lizard Anolis carolinensis moved to higher perches following invasion by Anolis sagrei and,

21 in response, adaptively evolved larger toepads after only 20 generations. These results illustrate

22 that interspecific interactions can drive evolutionary change on observable time scales.

24 One Sentence Summary: Island populations of the lizard Anolis carolinensis have rapidly

25 undergone morphological change in response to shifts in habitat use driven by competitive

26 interactions with an invading, closely related lizard. 
Main Text:

In their classic paper, Brown and Wilson (1) proposed that mutually negative interactions between closely-related species could lead to evolutionary divergence when those species cooccurred. In the six decades since, this idea has been debated vigorously, with support that has

32 vascillates based on the latest set of theoretical treatments and comparative studies (reviewed in

$33[(2-5)])$. However, tests of interaction-driven evolutionary divergence have been slow to

34 capitalize on the growing recognition that evolutionary change can occur rapidly in response to

35 strong divergent natural selection (but see [(6-9)]); thus, evolutionary hypotheses about

36 phenomena once thought to transpire on time scales too long for direct observation can be tested

37 in real time while using replicated statistical designs.

38 An opportunity to study real-time divergence between negatively interacting species has

39 been provided by the recent invasion of the Cuban brown anole lizard, Anolis sagrei, into the

40 southeastern United States, where Anolis carolinensis was the sole native anole. These species

41 have potential to interact strongly (e.g., [(10)]), being very similar in habitat use and ecology

42 (11). We investigated the eco-evolutionary consequences of this interaction on islands in Florida

43 (12) using an A. sagrei introduction experiment, well-documented natural invasions by A. sagrei,

44 genomic analyses of population structure, and a common garden experiment. This multifaceted

45 approach can rule against several of the most difficult alternative hypotheses (e.g., plasticity,

46 ecological sorting, environmental gradients $[(2,5)]$ ) while directly testing two predictions for

47 how A. carolinensis responds to its congeneric competitor.

$48 \quad$ Typical of solitary anoles (13), A. carolinensis habitat-use spans ground to tree crown

49 (14). However, where A. carolinensis and A. sagrei (or their close relatives) co-occur elsewhere,

50 A. carolinensis perches higher than A. sagrei (13-16). Thus, we used an introduction experiment

51 to test Collette's prediction (14) that competitive interactions with A. sagrei should drive an

52 increase in A. carolinensis perch height. In early May 1995, we chose six islands that contained

53 resident populations of $A$. carolinensis and collected pre-introduction perch height data from

54 undisturbed lizards (12). Later that month, we introduced small populations of A. sagrei to three

55 treatment islands, leaving three control islands containing only A. carolinensis (12). From May-

56 August 1995-1998, we measured perch heights for both species. The A. sagrei populations grew

57 rapidly (Table S1; [(17)]), and by August 1995, A. carolinensis on treatment islands already 
58 showed a significant perch height increase relative to controls, which was maintained through the 59 study (Fig. 1; Fig. S1; Table S2; [(12)]).

60 We next predicted, following (14), that this arboreal shift by A. carolinensis would drive

61 the evolution of larger toepads with more lamellae (adhesive, setae-laden, subdigital scales).

62 Toepad area and lamella number (body-size corrected) correlate positively with perch height 63 among anole species $(14,18-20)$. Larger and better developed toepads improve clinging ability

64 (20), permitting anoles to better grasp unstable, narrow, and smooth arboreal perches. We tested 65 the prediction in 2010 on a set of islands partially overlapping those used in 1995-1998 (12). We 66 surveyed 30 islands and found that $A$. sagrei had colonized all but five (12). We compared $A$.

67 carolinensis populations on these five islands without the invader (hereafter "un-invaded") to $A$. 68 carolinensis populations on six islands that, based on 1994 surveys, were colonized by A. sagrei 69 sometime between 1995 and 2010 (hereafter "invaded") (Fig. 2; [(12)]).

70 From May-August 2010, we measured perch height for undisturbed lizards and found

71 that, as in the 1995 introduction experiment, A. carolinensis perch height was significantly

72 higher on invaded islands (Fig. S2; Table S3; [(12)]). We then tested whether the perch height

73 shift had driven toepad evolution by measuring toepad area and lamella number of the $4^{\text {th }}$ toe of

74 each hindleg for every A. carolinensis captured (12). We found that $A$. carolinensis on invaded

75 islands indeed had larger toepads and more lamellae (traits corrected for body size; Fig. 3; Table 76 S3; $[(12)])$.

77 This morphological change occurred quickly. Assuming conservatively that A. sagrei

78 reached all six invaded islands in 1995, A. carolinensis populations on invaded and un-invaded

79 islands have diverged at mean rates of 0.091 (toepad area) and 0.077 (lamellae) standard

80 deviations per generation (haldanes [(21)]; rates $>$ zero, each one-tailed $p<0.02 ;[(12)]$ ),

81 comparable to other examples of rapid evolution (21) such as soapberry bug beak length (22) or

82 guppy life history (23).

83 We tested several alternative processes that could have generated the observed

84 divergence. First, we used a common garden experiment to investigate possible post-hatching,

85 developmental responses to physical challenges imposed by arboreality during growth (i.e.,

86 phenotypic plasticity). We took gravid A. carolinensis females from four invaded and four un-

87 invaded islands in July 2011, collected their eggs in the lab, and raised the offspring in identical 88 conditions (12). The effect of $A$. sagrei invasion on A. carolinensis toepad characteristics 
89 persisted in the common garden (Fig. 3; Table S4; [(12)]), suggesting genetically based

90 divergence in nature (though we cannot rule out trans-generational plasticity).

91 Second, observed divergence in A. carolinensis could have arisen through non-random

92 migration of individuals with large toepads among invaded islands, instead of independently on

93 each island. Thus, we tested whether relatedness among $A$. carolinensis populations is

94 independent of A. sagrei invasion. In 379 A. carolinensis individuals from 4 un-invaded and 5

95 invaded islands, we genotyped 121,973 single nucleotide polymorphisms across the genome

96 (Table S5, [(12)]). Individuals from the same island were closely related, and islands were

97 largely genetically independent (pairwise- $F_{\mathrm{ST}}$ 0.09-0.16; Table S6). We found no evidence that

98 population relatedness in A. carolinensis was correlated with whether an island had been

99 colonized by A. sagrei (Fig. 4; [(12)]) or with distance between islands (Mantel test; $p>0.25$ ),

100 suggesting that gene flow is relatively limited among islands and that island populations were

101 independently founded from the mainland.

102 Third, toepad changes could have been generated by adaptation to environmental

103 differences among islands that are confounded with the presence of A. sagrei [e.g., (24)].

104 Invaded and un-invaded islands, however, do not differ in characteristics important to perching

105 or arboreal locomotion (e.g., vegetated area, plant species richness, or available tree heights;

106 Table S7; [(12)]). Fourth, toepad changes could have arisen through ecological sorting, wherein

107 A. sagrei was only able to colonize those islands on which the existing A. carolinensis

108 population was already sufficiently different. However, $A$. sagrei seems capable of successfully

109 colonizing every island it reaches, regardless of resident $A$. carolinensis ecology/morphology: all

110 ten A. sagrei populations introduced in 1994-1995 are still extant (12), and A. sagrei inhabits

111 nearly every other island surveyed in the lagoon (Fig. 2). Finally, toepad changes observed in

1122010 could be unrelated to interactions with $A$. sagrei if the latter's invasion merely missed the

113 five islands with the lowest $A$. carolinensis perch heights (Fig. S2) by chance; however, this

114 would occur only one time in 462. In sum, alternative hypotheses of phenotypic plasticity,

115 environmental heterogeneity, ecological sorting, non-random migration, and chance are not

116 supported; our data suggest strongly that interactions with $A$. sagrei have led to evolution of

117 adaptive toepad divergence in A. carolinensis.

118 Brown and Wilson called evolutionary divergence between closely related, sympatric

119 species 'character displacement' (1), and our data constitute a clear example. Resource 
120 competition has been the interaction suggested most often as the source of divergent selection

121 during character displacement (sometimes specifically called 'ecological character displacement'

$122[(1-3)])$. For A. carolinensis and A. sagrei, resource competition for space likely is important:

123 allopatric $A$. carolinensis and $A$. sagrei overlap in their use of the habitat $(12-14,16)$; moreover,

124 when they co-occur, the two species interact agonistically (10), and our experimental data show a

125 rapid spatial shift by $A$. carolinensis following A. sagrei introduction. The two species also

126 overlap in diet and thus may compete for food (17). Competition for food is strong among co-

127 occurring Anolis and has been shown to be mitigated by differences in perch height (11).

128 Evolutionary divergence may also arise, however, from selection to reduce interspecific

129 hybridization, yet such 'reproductive character displacement' (4) seems an unlikely explanation

130 for our results as A. carolinensis and A. sagrei already differ markedly in species-recognition

131 characteristics, males of both species nearly exclusively ignore heterospecifics in staged

132 encounters (25), and the species have never been reported to successfully produce hybrids. We

133 note, finally, that other mutually negative interactions like apparent competition (26) and

134 intraguild predation (27) could also produce divergence among overlapping species. These

135 remain to be explored in this system, though some evidence exists for at least the latter (17).

136 Here, we have provided evidence from a replicated, natural system to support the long-

137 held idea (4) that interspecific interactions between closely related species are an important force

138 for evolutionary diversification (2). Moreover, we show that evolutionary hypotheses like

139 character displacement can be rigorously tested in real time following human-caused

140 environmental change. Our results also demonstrate that native species may be able to respond

141 evolutionarily to strong selective forces wrought by invaders. The extent to which the costs of

142 invasions can be mitigated by evolutionary response remains to be determined (28), but studies

143 such as this demonstrate the ongoing relevance of evolutionary biology to contemporary

144 environmental issues.

146 References and Notes:

147 1. W. L. Brown, E. O. Wilson, Character displacement. Systematic Zoology 5, 49-64 (1956).

148 2. D. Schluter, The Ecology of Adaptive Radiation (Oxford University Press, Oxford, UK, 149 2000).

150 3. T. Dayan, D. Simberloff, Ecological and community-wide character displacement: the 
next generation. Ecology Letters 8, 875-894 (2005).

152 4. D. W. Pfennig, K. S. Pfennig, Evolution's Wedge (University of California Press,

153 Berkeley, USA, 2012).

154 5. Y. E. Stuart, J. B. Losos, Ecological character displacement: glass half full or half empty?

155 Trends in Ecology and Evolution 28, 402-408 (2013).

156 6. P. R. Grant, B. R. Grant, Evolution of character displacement in Darwin's finches. Science 157 313, 224-226 (2006).

$1587 . \quad$ J. G. Tyerman, M. Bertrand, C. C. Spencer, M. Doebeli, Experimental demonstration of 159 ecological character displacement. BMC Evolutionary Biology 8, 34 (2008).

1608 2. M. Bono, C. L. Gensel, D. W. Pfennig, C. L. Burch, Competition and the origins of 161 novelty: experimental evolution of niche-width expansion in a virus. Biology Letters 9 , $162 \quad 20120616(2013)$.

163 9. M. L. Taper, in Bruchids and legumes: economics, ecology, and coevolution, K. Fujii, A. 164 Gatehouse, C. D. Johnson, R. Mitchel, T. Yoshida, Eds. (Kluwer Academic Publishers, 165 1990), pp. 289-301.

10. J. R. Edwards, S. P. Lailvaux, Do interspecific interactions between females drive shifts in

11. J. B. Losos, Lizards in an Evolutionary Tree: Ecology and Adaptive Radiation of Anoles of the Linnean Society 110, 843-851 (2013).

171 12. Information on materials and methods is available on Science Online.

172 13. T. W. Schoener, Presence and absence of habitat shift in some widespread lizard species.

173 Ecological Monographs 45, 233-258 (1975).

174 14. B. B. Collette, Correlations between ecology and morphology in anoline lizards from Havana, Cuba, and southern Florida. Bulletin of the Museum of Comparative Zoology 125, 137-162 (1961).

177 15. L. R. Schettino et al., The Anoles of Soroa: aspects of their ecological relationships. Breviora 520, 1-22 (2010).

179 16. J. R. Edwards, S. P. Lailvaux, Display behavior and habitat use in single and mixed populations of Anolis carolinensis and Anolis sagrei lizards. Ethology 118, 494-502 (2012).

182 17. T. S. Campbell, thesis, University of Tennessee, Knoxville (2000).

183 18. D. Glossip, J. B. Losos, Ecological correlates of number of subdigital lamellae in anoles. 
Herpetologica 53, 192-199 (1997).

185 19. T. E. Macrini, D. J. Irschick, J. B. Losos, Ecomorphological differences in toepad characteristics between mainland and island anoles. Journal of Herpetology 37, 52-58 (2003).

20. J. Elstrott, D. J. Irschick, Evolutionary correlations among morphology, habitat use and clinging performance in Caribbean Anolis lizards. Biological Journal of the Linnean Society 83, 389-398 (2004).

191 21. A. P. Hendry, M. T. Kinnison, Perspective: the pace of modern life: measuring rates of contemporary microevolution. Evolution 53, 1637-1653 (1999).

22. S. P. Carroll, C. Boyd, Host race radiation in the soapberry bug: natural history with the history. Evolution 46, 1052-1069 (1992).

23. D. N. Reznick, F. H. Shaw, F. H. Rodd, R. G. Shaw, Evaluation of the rate of evolution in natural populations of guppies (Poecilia reticulata). Science 275, 1934-1937 (1997).

24. S. Meiri, D. Simberloff, T. Dayan, Community-wide character displacement in the presence of clines: A test of Holarctic weasel guilds. Journal of Animal Ecology 80, 824 834 (2011).

25. R. R. Tokarz, J. W. Beck Jr, Behaviour of the suspected lizard competitors Anolis sagrei and Anolis carolinensis: an experimental test for behavioural interference. Animal Behaviour 35, 722-734 (1987).

26. R. D. Holt, Predation, apparent competition, and the structure of prey communities. Theoretical Population Biology 12, 197-229 (1977).

27. G. A. Polis, C. A. Myers, R. D. Holt, The ecology and evolution of intraguild predation: potential competitors that eat each other. Annual Review of Ecology and Systematics 20, 297-330 (1989).

28. R. Shine, Invasive species as drivers of evolutionary change: cane toads in tropical Australia. Evolutionary Applications 5, 107-116 (2012).

29. M. Tollis, S. Boissinot, Genetic variation in the green anole lizard (Anolis carolinensis) reveals island refugia and a fragmented Florida during the quaternary. Genetica 142, 5972 (2014).

30. T. S. Campbell, A. C. Echternacht, Introduced species as moving targets: changes in body sizes of introduced lizards following experimental introductions and historical invasions. (1964). 
32. A. Gelman, J. Hill, Data Analysis Using Regression and Multilevel/Hierarchical Models. (Cambridge University Press, Cambridge, UK, 2007).

220 33. J. Pinheiro, D. Bates, S. DebRoy, D. Sarkar, nlme: linear and non-linear mixed effects models. R package version 3.1-117 (2014).

222 34. J. Oksanen, F. G. Blanchet, R. Kindt, P. Legendre, vegan: community ecology package version 2.0-8. http://Cran.R-project.org/package=vegan (2013).

35. B. C. Lister, The nature of niche expansion in West Indian Anolis lizards I: ecological consequences of reduced competition. Evolution, 659-676 (1976).

36. B. C. Lister, The nature of niche expansion in West Indian Anolis lizards II: evolutionary components. Evolution 30, 677-692 (1976).

37. M. K. Hecht, Natural selection in the lizard genus Aristelliger. Evolution 6, 112-124 (1952).

38. P. D. Etter, S. Bassham, P. A. Hohenlohe, E. A. Johnson, W. A. Cresko, SNP discovery and genotyping for evolutionary genetics using RAD sequencing. Molecular methods for evolutionary genetics 772, 157-178 (2011).

39. J. Catchen, P. A. Hohenlohe, S. Bassham, A. Amores, W. A. Cresko, Stacks: an analysis tool set for population genomics. Molecular Ecology 22, 3124-3140 (2013).

40. B. Langmead, S. L. Salzberg, Fast gapped-read alignment with Bowtie 2. Nature Methods 9, 357-359 (2012).

237 41. P. A. Hohenlohe et al., Population genomics of parallel adaptation in threespine stickleback using sequenced RAD tags. PLoS Genetics 6, e1000862 (2010).

42. D. H. Huson, D. Bryant, Application of phylogenetic networks in evolutionary studies. Molecular Biology and Evolution 23, 254-267 (2006).

43. D. Bryant, V. Moulton, in Algorithms in Bioinformatics, Lecture Notes in Computer Science. R. Guigo, D. Gusfeld, Eds. (Springer Berlin Heidelberg, Berlin, Heidelberg, 2002), vol. 2452, pp. 375-391.

44. B. S. Weir, C. C. Cockerham, Estimating F-statistics for the analysis of population structure. Evolution 38, 1358-1370 (1984).

45. E. Paradis, J. Claude, K. Strimmer, APE: Analyses of Phylogenetics and Evolution in R language. Bioinformatics 20, 289-290 (2004).

249 We thank A. Kamath, C. Gilman, A. Algar, J. Allen, E. Boates, A. Echternacht, A. Harrison, H. 250 Lyons-Galante, T. Max, J. McCrae, J. Newman, J. Rifkin, M. Stimola, P. VanMiddlesworth, K. 
251 Winchell, C. Wiench, K. Wollenberg, and three reviewers; M. Legare and J. Lyon (Merritt Island 252 National Wildlife Refuge), J. Stiner and C. Carter (Canaveral National Seashore); Harvard 253 University, Museum of Comparative Zoology, University of Massachusetts, University of 254 Tennessee, University of Tampa, NSF (DEB-1110521) and NIH (P30GM103324) for funding. 255 Y.E.S., T.S.C., and J.B.L. designed the study; Y.E.S., T.S.C., P.A.H., L.J.R, and R.G.R.

256 collected the data; Y.E.S., T.S.C., and P.A.H. analyzed the data; all authors contributed to the 257 manuscript. Data are accessioned on datadryad.org:xxxxxxxx.

258

\section{Supplementary Materials:}

260 www.sciencemag.org/content/\#\#\#/\#\#\#/\#\#\#\#/suppl/XX\#

261 Materials and Methods

262 Figs. S1 to S2

263 Tables S1 to S7

264 References (29-45) 


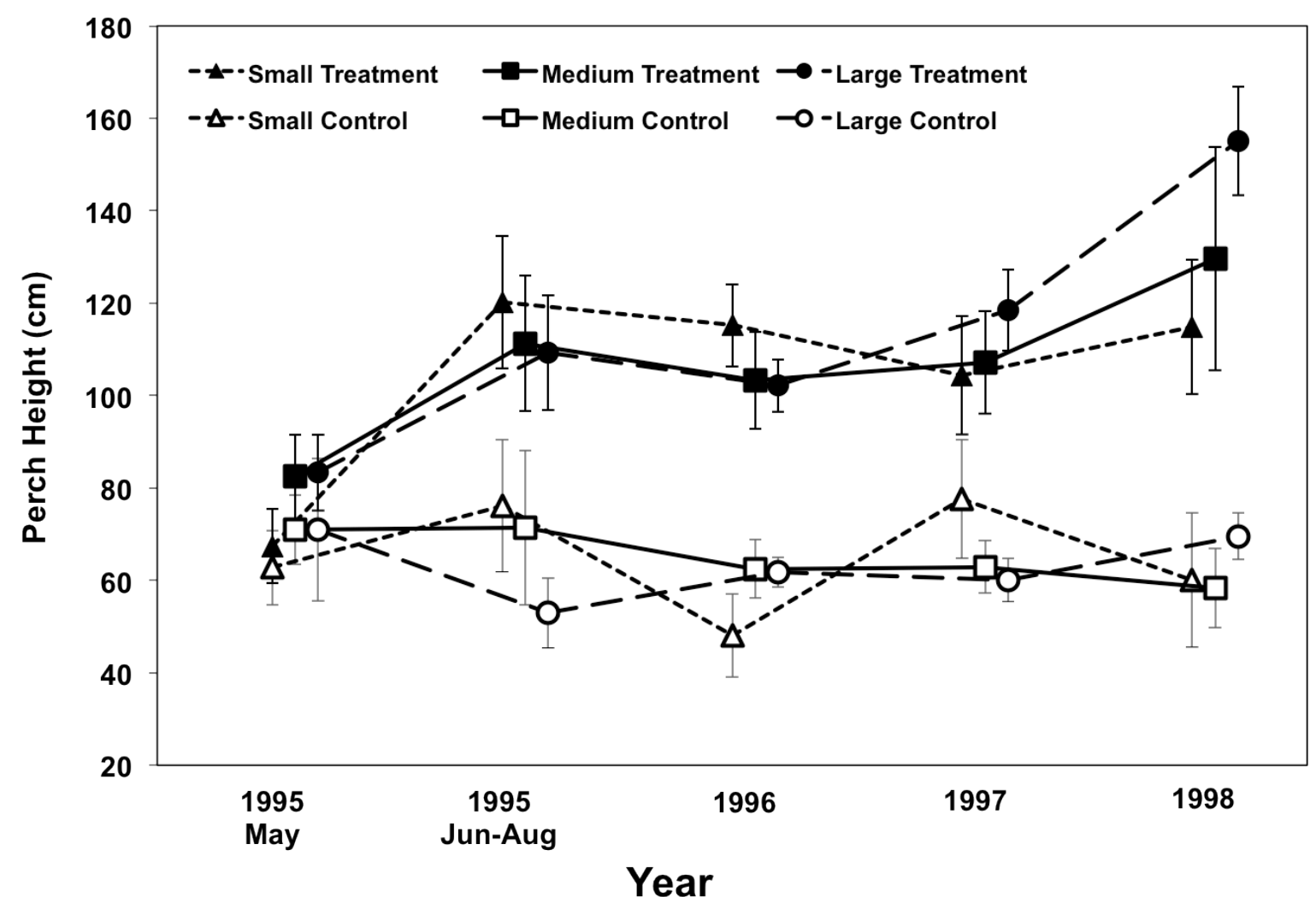

268 Fig. 1. Perch height shift by $A$. carolinensis after the experimental introduction of $A$. sagrei.

269 We introduced A. sagrei to one small, one medium, and one large island (treatment; closed

270 shapes) in 1995, keeping three similarly-sized control islands (open shapes). Island means

271 ( \pm 1 s.e.) are shown for perch height. Anolis sagrei introduction corresponds with a significant

272 perch height increase by $A$. carolinensis (Linear Mixed Models: treatment $\mathrm{x}$ time interactions, all $273 p<0.001$; [(12)]; Table S1; Table S2). 


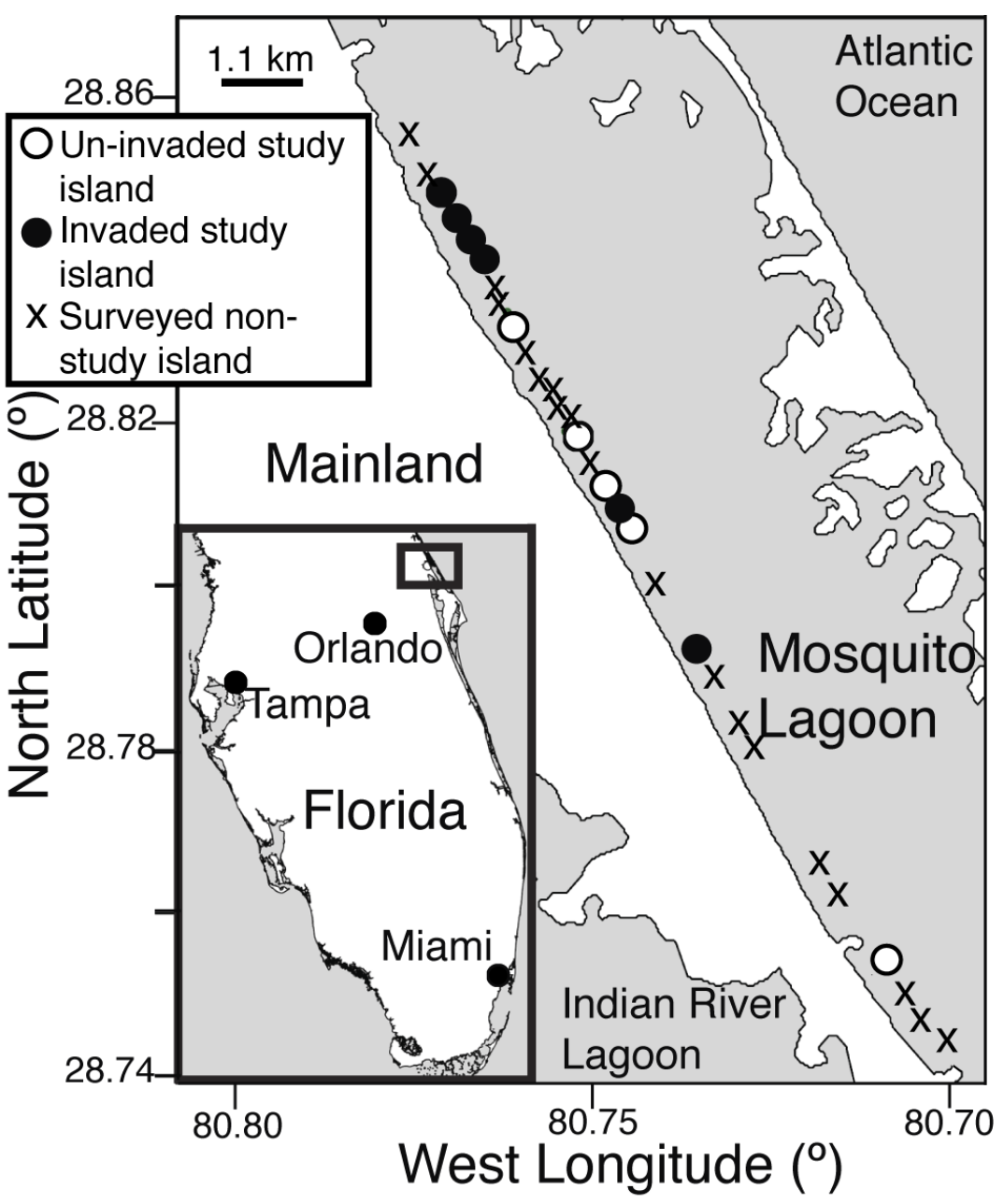

Fig. 2. 2010 study islands along the Intracoastal Waterway. Anolis carolinensis inhabits all

277 study islands. Six study islands were invaded by A. sagrei sometime between 1995 and 2010

278 (closed circles) and five study islands remain un-invaded today (open circles). 19 additional non-

279 study islands were surveyed (' $\mathrm{X}$ '; [(12)]); 17 were invaded by $A$. sagrei and two were empty of 280 both species. 


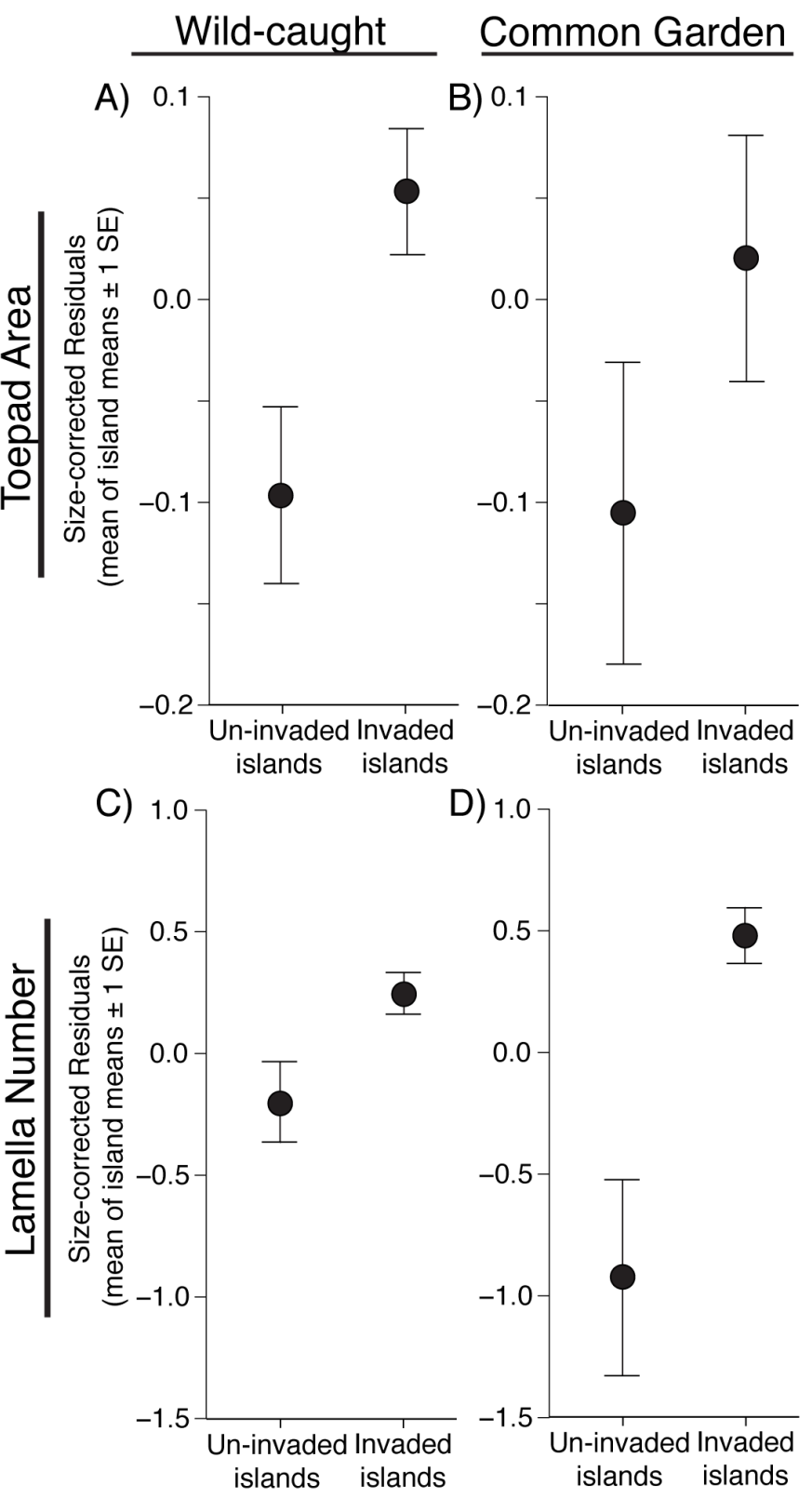

282 Fig. 3. Divergence in wild-caught $(\mathrm{A}, \mathrm{C})$ and common garden $\boldsymbol{A}$. carolinensis (B, D). Mean-

283 of-island-means, size-corrected residuals ( \pm 1 s.e.) are shown. The invasion of $A$. sagrei

284 corresponds to a significant increase in both traits for wild-caught lizards (A, C) in 2010 (5

285 islands un-invaded, 6 invaded; Linear Mixed Models [LMM]; Panel A: Toepad Area, $\beta_{\text {invaded }}$

$286=0.15, t_{9}=2.7, p=0.012$; Panel C: Lamella Number, $\left.\beta_{\text {invaded }}=0.54, t_{9}=3.1, p=0.009\right)$. Common

287 garden offspring from invaded islands had significantly larger toepad characteristics (4 un-

288 invaded islands; 4 invaded; LMM; Panel B: Toepad Area, $\beta_{\text {invaded }}=0.14, t_{6}=2.1, p=0.043$; Panel

289 D: Lamella Number, $\left.\beta_{\text {invaded }}=1.45, t_{6}=3.6, p=0.006\right)$. All $p$-values one-tailed. 


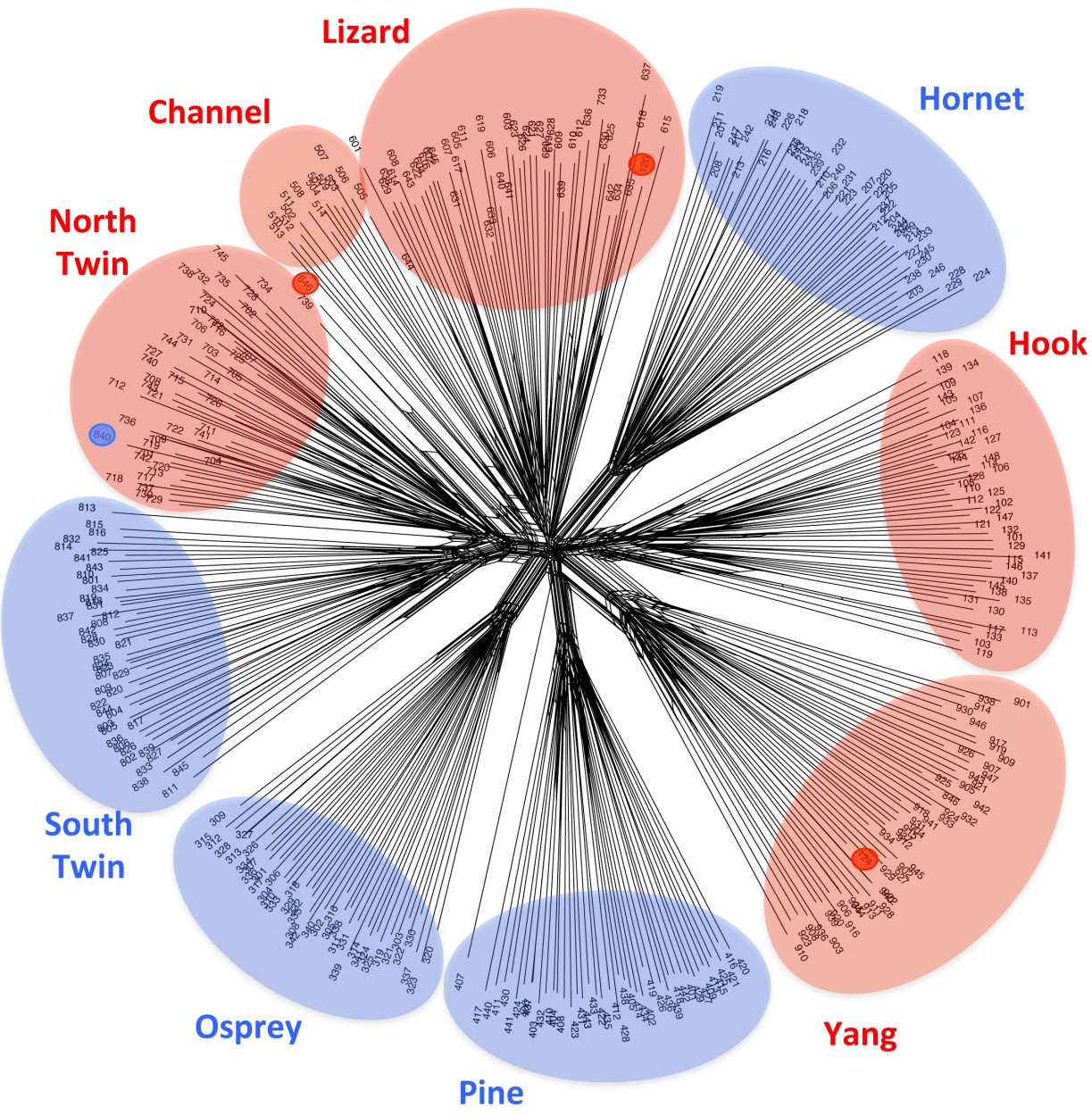

292 Figure 4. Neighbor-net analysis of genetic distance for $\boldsymbol{A}$. carolinensis individuals from

293 invaded (red) and un-invaded (blue) islands (12). Small shaded areas enclose individuals that

294 do not cluster with their own island; the color of these areas represents invasion status of their 295 home islands. 
297 Supplementary Materials:

298 Materials and Methods

299 Tables S1-S7

300 Figures S1-S2

301 References (31-44)

302 Full Acknowledgments

303

304 Materials and Methods:

305 Terminology

306 The terms native, invasive, invaded, natural, and introduced have accrued multiple

307 connotations across the invasive species literature. Therefore, we define our use of these terms

308 here. We treat $A$. carolinensis as a native species because it has existed on the mainland United

309 States for ca. 2 million years (29). Anolis carolinensis is ubiquitous in the Mosquito Lagoon

310 region and its colonization of the spoil islands does not constitute a range expansion; therefore,

311 we consider it a native species on the spoil islands even though colonization of those man-made

312 islands is recent. By contrast, A. sagrei is native to Cuba and the Bahamas. It colonized southern

313 Florida in the 1940s (14) and spread into the rest of Florida as well as Georgia and Louisiana.

314 Hence, we refer to A. sagrei as an invasive species, and we term the spoil islands on which it has

315 established populations as invaded. Furthermore, we wish to make a distinction between

316 colonization by $A$. sagrei that is the result of natural processes versus those that are purposefully

317 manipulated by researchers. We term those instances where we purposefully colonized islands

318 with A. sagrei as introductions; thus, the 1995-1998 study is an introduction experiment.

We first discuss the natural history of the dredge spoil islands and then describe the two

321 studies reported in the main text: (1) the 1995-1998 introduction experiment, and (2) the 2010

322 study of character displacement in toepad characteristics.

324 Dredge Spoil Island Natural History

325 The Mosquito Lagoon dredge spoil islands used in these studies were created by the US

326 Army Corps of Engineers (17) as a byproduct of the digging of the Intracoastal Waterway

327 (ICW). An old, obsolete section of ICW channel built prior to the 1950s exists along the eastern 
328 edge of the lagoon. The new, active channel of the ICW was dredged along the western edge of 329 the lagoon in the 1950s. Spoil islands exist along both the old and the active channel.

330 Along with other flora and fauna from the nearby mainland, A. carolinensis colonized the 331 islands in the decades following island creation (17). We observed A. carolinensis in

332 (presumably) marginal mangrove and salt marsh environments on every island visited in 2010.

333 This suggests that $A$. carolinensis populations could have reached the islands through natural

334 colonization shortly after the creation of the islands without requiring the late-successional,

335 present-day plant community dominated by broad-stemmed woody species (e.g., Juniperus

336 virginiana and Sabal palmetto). Anolis sagrei arrived to the mainland surrounding the lagoon in

337 the late 1980 s (30).

338 But for the occasional nocturnal gecko (Hemidactylus sp.), we observed no other lizards

339 on the islands during research from 2009-2011. The bird faunas on these islands are depauperate

340 and mostly feature waterfowl; we observed red-winged blackbirds (Agelaius phoeniceus) and

341 common nighthawks (Chordeiles minor) infrequently, and other insectivorous birds were

342 observed even more rarely, suggesting little competition for insects with the Anolis species from

343 birds. Several spider species inhabited the islands at noticeable frequency (Nephila clavipes,

344 Gasteracantha cancriformis, Argiope aurantia, Eriophora ravilla, Phidippus spp.), but their

345 competitive relationship with the lizards on these islands remains to be studied (see [(11)] for

346 discussion of anole-spider interactions). The most commonly observed lizard predators on these

347 islands were black racers (Coluber constrictor) and raccoons (Procyon lotor). Racers were seen

348 only occasionally and not often enough to compare invaded and un-invaded islands. We did not

349 collect quantitative data on raccoons but they were observed on nearly every island and likely

350 only prey on lizards opportunistically. Very little is known about parasites in A. carolinensis and

351 A. sagrei (see $[(11)])$. Occasionally, we observed unidentified insect larvae that were living

352 subcutaneously emerge through the skin of adult $A$. carolinensis.

353

354 (1) Introduction Experiment (1995-1998)

355 A pilot introduction of $A$. sagrei to Six-Palm and Coon Islands indicated that $A$. sagrei

356 populations would expand rapidly following introduction (30). To assess the speed and

357 magnitude of the effects of $A$. sagrei invasion on $A$. carolinensis demography and habitat use, we

358 conducted an introduction experiment on six spoil islands in Mosquito Lagoon from 1995 to 
359 1998. We chose matched pairs of small (ca. 0.1 ha), medium (ca. 0.2 ha), and large (ca. 1.0 ha)

360 islands and flipped a coin to determine which island in each pair would be subjected to a

361 purposeful introduction of $A$. sagrei (Table S1) in a random-blocked design. Throughout May

362 1995, before initiating the $A$. sagrei introductions, we sampled $A$. carolinensis on all six islands

363 using Rand surveys (31), whereby we walked through the habitat slowly until we observed an

364 undisturbed adult lizard. We then measured its perch height to the nearest $1 \mathrm{~cm}$ using a tape

365 measure. We marked all lizards with unique numbers (with permanent markers and by toe-

366 clipping) to prevent double-counting; thus, all lizards in the perch height analyses were unique

367 individuals. On May 27 and 28, 1995, we captured 120 A. sagrei from urban sites on the

368 surrounding mainland near New Smyrna Beach and marked and released 40 of these $A$. sagrei

369 (20M:20F) on each of the three treatment islands. We only observed four A. sagrei on the large

370 treatment island in the few weeks subsequent to their release, so we increased propagule pressure

371 by adding 40 more $A$. sagrei to this island in early June 1995 to encourage the establishment on

372 this much larger island. From June through August 1995, and throughout the summers (May to

373 August) of 1996, 1997, and 1998, we used the same methods to collect perch height data for $A$.

374 carolinensis and the introduced A. sagrei populations.

375 The small treatment (ST) and small control (SC) islands are located on the eastern edge

376 of Mosquito Lagoon in the old channel of the ICW near Eldora, FL (28.91, -80.82; [(17)]). Island

377 ST, $0.5 \mathrm{~km}$ north of Eldora, is 0.16 ha in total area, with a central forested area of 0.04 ha

378 (dominant species: Juniperus virginiana, Schinus terebinthifoliusis, Sabal palmetto) flanked on

379 the north, east, and south by extensive regularly inundated salt marsh (Spartina alterniflora and

380 Batis sp.). Island SC, $0.2 \mathrm{~km}$ south of Eldora, is 0.12 ha in total area, with a central forested area

381 of 0.02 ha (same dominant species) flanked on the east and south by a narrow strip of regularly

382 inundated salt marsh (Spartina alterniflora and Batis sp.). The medium treatment (MT) is located

383 in the island chain along the western edge of Mosquito Lagoon (where the 2010 toepad study

384 was conducted) and is 0.17 ha, with vegetation the same as ST and SC, but the forested area

385 (0.10 ha) comprises a larger percentage of this island, and the salt marsh only occurs on the north

386 and west edges. The medium control (MC; $0.15 \mathrm{ha})$ is also located along the western edge of

387 Mosquito Lagoon near the south end of the island chain. It is very similar to Island MT in

388 forested area (0.08 ha) and marsh area, which only flanks the south and east edges of the island. 
389 Finally, the small and medium islands are similar to the large islands in that they represent 390 smaller versions of the forested area on the large islands and support similar vegetation (17).

391 The two large treatment and control islands (LT and LC, respectively) are also located on

392 the western edge of Mosquito Lagoon along the new, active channel of the ICW. Both are large

393 sand piles with open, desert-like central areas rimmed by forested 'hedges' and relatively small,

394 triangular, marsh 'tails' extending westward towards the mainland. LT (0.89 ha) has 0.21 ha

395 forested area composed of Juniperus virginiana, Schinus terebinthifoliusis, and Sabal palmetto.

396 LC (0.94 ha) is physically very similar to Island LT, with 0.16 ha forested area. LC, a National

397 Park Service backcountry campsite is frequently used by boaters, and thus was naturally invaded

398 by $A$. sagrei at the end of the introduction experiment in 1998. We removed a few A. sagrei in

399 early May of 1998 to maintain its integrity as a control island for the introduction experiment

400 throughout that summer. By 2010, this LC population of A. sagrei was fully established; both LT

401 and LC were used as invaded islands for the 2010 toepad study, described next (Table S1). (MC

402 and SC were also invaded naturally by A. sagrei between 1998 and 2010).

403 For the 1995-1998 introduction experiment, we used linear mixed models to analyze $A$.

404 carolinensis perch height data because such models incorporate within-island variation by

405 nesting islands as a random effect within the fixed treatment effect (i.e., the introduction of $A$.

406 sagrei) (32). We square-root transformed the perch data to improve normality in the model

407 residuals. We termed the variable representing the five time points during which perch heights

408 were measured "event"; "event" included 1995 pre-introduction (May), 1995-post introduction

409 (June - August), 1996, 1997, and 1998. We conducted our analyses using the lme() function in

410 the R package nlme (33) and built the following full model that includes treatment, event, and

411 sex as explanatory variables: 1 me $(\operatorname{sqrt}($ perch height $) \sim$ treatment + event + sex + treatment*event

$412+$ treatment*sex, random $=\sim \operatorname{sex} \mid$ island). The treatment*sex interaction was not significant so

413 we built the following reduced model: $\operatorname{lme}(\operatorname{sqrt}($ perch height $) \sim$ treatment + event $+\operatorname{sex}+$

414 treatment*event, random $=\sim \operatorname{sex} \mid$ island). Residuals from this model were normally distributed

415 and model output is reported in Table S2. The treatment*event interaction was significant, as

416 would be expected if $A$. sagrei drives a perch height increase in A. carolinensis. At each time

417 point post introduction of $A$. sagrei, A. carolinensis perches significantly higher on treatment

418 islands compared to controls (Table S2; ( $\beta_{\text {treatment }}$ ranges from 2.09 to 3.47, $t_{1627}$ ranges from 3.3

419 to 5.0; all one-tailed $p<0.001)$. Male lizards perch significantly higher than females $\left(\beta_{\text {male }}=\right.$ 
$4201.85, t_{1627}=10.1$, one-tailed $\left.p<0.001\right)$. Treatment itself was not significant in this model $(p>$

421 0.36; Table S2) because $A$. carolinensis perch heights were measured on treatment islands

422 before $A$. sagrei introduction in early 1995 (Fig. 1). To investigate the effects of treatment

423 further, we built the same model but for a dataset pruned to include only perch height data

424 collected post-introduction. This model found that sex remained a significant predictor of $A$.

425 carolinensis perch height $\left(\beta_{\text {male }}=1.95, t_{1384}=10.0\right.$, one-tailed $\left.p<0.001\right)$. The treatment effect

426 was significant in this model $\left(\beta_{\text {treatment }}=2.98, t_{4}=5.4\right.$, one-tailed $p<0.003$; Table S2), but the

427 treatment*event interaction was no longer significant (all $p>0.39$; Table S2). This is consistent

428 with Fig. 1: most perch height shift occurred in 1995 just after introduction, and perch height

429 remained mostly level 1996-1998.

431 (2) Character Displacement in Toepads (2010)

432 We wanted to determine whether a perch height shift by $A$. carolinensis in response to the 433 invasion of $A$. sagrei drove toepad evolution in the former species. From presence absence

434 surveys in 2009 and 2010, we found five islands un-invaded by A. sagrei with only $A$.

435 carolinensis present. We compared perch heights and toepads of $A$. carolinensis populations on 436 these islands to $A$. carolinensis on six islands where $A$. sagrei had invaded. The six invaded 437 islands were chosen because they were similar in size, shape, and vegetation to the un-invaded 438 islands (see below).

Study Island History and Choice, and Accounting for Environmental Heterogeneity

In 1994, along the western edge of Mosquito Lagoon following the main channel of the

442 ICW, Campbell surveyed for A. carolinensis and A. sagrei on 23 spoil islands. Of these 23

443 islands, all but two had populations of $A$. carolinensis. Of the 21 islands with $A$. carolinensis on

444 them, by 1994, two islands were already invaded by A. sagrei. Four more of these 21 islands had

445 A. sagrei purposefully introduced to them in 1994 and 1995: LT and MT from the introduction

446 experiment described above, and islands Six-Palm and Coon as part of a separate pilot study

447 described in (30). By the end of the introduction experiment, island LC had been colonized

448 naturally by $A$. sagrei, bringing the total invaded to seven of the 21 . We surveyed these 23

449 islands again in 2009 and 2010 and found that $A$. sagrei had also invaded 12 more islands

450 through natural colonization (including MC from the introduction experiment), leaving just two 
451 islands of the original 23 with just $A$. carolinensis (recall that two islands were empty in 1994

452 and remained so in 2010). We surveyed 7 more islands along the western edge of the lagoon,

453 revealing three additional islands with only $A$. carolinensis, making for a total of 5 un-invaded

454 islands with just $A$. carolinensis out of 30 islands surveyed. Thus, we chose these 5 islands as our

455 "controls" and complemented them with six "treatment" islands from the original 23 that were

456 similar to the controls in size, shape, and vegetation structure but were invaded by A. sagrei

457 sometime between 1995 and 2010 (Table S3). The five un-invaded islands are interspersed

458 between invaded islands (Fig. 2). Two of the six invaded islands (LC and LT) were part of the 459 introduction experiment described above.

460 We did not use MT, MC, ST, or SC because they were much smaller than required, 461 compared to the five un-invaded "control" islands. Beyond LT, MT, and ST, seven more 462 purposeful introductions of $A$. sagrei were made by Campbell: two on the western edge of the 463 lagoon along the new, active ICW channel in 1994 (Six-Palm and Coon described above; [(30)]), 464 and five in 1995 on the eastern edge of the lagoon along the old ICW channel. Similarly, these 465 five introduced old-channel islands were not used because they were not comparable to the five 466 controls in size or age. However, that 10 of 10 purposeful introductions of A. sagrei were 467 successful on islands that varied in size and age suggests that $A$. sagrei can colonize any spoil 468 island and that ecological sorting is not responsible for the patterns observed in 2010 (see main 469 text).

We tested for environmental heterogeneity between invaded and un-invaded islands in 472 island in the study, we used Google Earth. We used logistic regression to test whether these 473 variables are associated with the presence or absence of $A$. sagrei (Table S7).

474 To test for differences in available tree heights and vegetation species richness, we 475 conducted point-quarter habitat surveys of island vegetation. Islands have two distinct habitat 476 types: a forested edge and an open center. Within the forested edge, we used Google Earth to 477 haphazardly choose survey points along an outer circle close to the forest/water edge and an 478 inner circle near the forest/center edge. For the open center, we surveyed three to four points 479 along three to four regularly placed north-south transects, the number of points and transects per 480 island depending on island size. At each point, we recorded the species identity for the four 481 closest trees (one in each quarter) and then measured their heights. We also recorded the species 
482 identities of the four closest shrubs (one in each quarter). As above, we used logistic regression

483 with invaded/un-invaded status as the response variable and available tree heights and two

484 species richness metrics were used as the predictor variables. Species richness was calculated

485 using both the Shannon and Simpson diversity indices using the diversity() function in the $\mathrm{R}$

486 (version 2.14.1, R Development Core Team) package vegan (34). Results are shown in Table $487 \quad$ S7.

of $A$. sagrei, as found in the introduction experiment, we visited each island on average 8.3 times

492 from May-August 2010, usually visiting sometime between 7am and 2pm. We collected lizard

493 perch height data using the Rand survey method (31), whereby we walked through the habitat

494 slowly until we observed an undisturbed adult lizard. We noted the perch at which the lizard was

495 first observed and measured the height of the perch to the nearest $\mathrm{cm}$ with a tape measure.

496 Sample sizes are in Table S3.

497 We again used linear mixed models to analyze perch height data (32). We square-root

498 transformed the perch data to improve normality in the model residuals. We conducted our

499 analyses using the lme() function in the R package nlme (33) and built a full model that includes

500 sex as an explanatory variable as follows: lme(sqrt(lizard perch height) $\sim$ sagrei presence + sex +

501 sagrei presence $*$ sex, random $=\sim \operatorname{sex} \mid$ island). The interaction term in the full model was not

502 significant so we built the following reduced model: lme(sqrt(lizard perch height) sagrei

503 presence + sex, random $=\sim \operatorname{sex} \mid$ island). Residuals from this model were normally distributed.

504 The presence of $A$. sagrei significantly predicts perch height in $A$. carolinensis populations (see

505 main text for statistics), even after significant perch differences by sex are taken into account

$506 \quad\left(\beta_{\text {male }}=1.94, t_{807}=3.7\right.$, one-tailed $\left.p<0.001\right)$.

$507 \quad$ Previous studies of Anolis have found that limb length correlates positively with lizard

508 perch diameter (reviewed in $[(11)]$ ), so we also measured diameter of lizard perches to the

509 nearest $0.1 \mathrm{~cm}$. We found no difference in perch diameter use by $A$. carolinensis on invaded and

510 un-invaded islands (Linear Mixed Model, log-transformed data, no interaction: $\beta_{\text {invaded island }}=$

$5110.17, t_{9}=1.49, p=0.17 ; \beta_{\text {male }}=-0.02, t_{768}=-0.27, p=0.29$; island sample sizes 52-108), so there

512 was no functional basis to predict limb length evolution. Thus, we focused solely on the 
513 prediction that $A$. sagrei should drive the evolution of enhanced toepads in sympatric $A$.

514 carolinensis.

515 The focus of both the 1995-1998 introduction experiment and the 2010 study has been

516 the influence of the invader A. sagrei on habitat use and morphology in A. carolinensis. We

517 weren't able to ask the converse, whether $A$. carolinensis influences $A$. sagrei perch use (and

518 subsequently toepad morphology), because of a dearth of comparable islands with just $A$. sagrei

519 present. However, comparisons among populations throughout the Caribbean suggest that $A$.

520 carolinensis does indeed influence $A$. sagrei ecomorphology. Compared to populations where $A$.

521 sagrei is the lone anole, A. sagrei sympatric with A. carolinensis perch lower $(13,35)$ and have

522 fewer lamellae (36). This suggests that the negative interactions between the two species are

523 indeed mutual although perhaps not always symmetric. On the spoil islands, we should expect

524 the response to be asymmetrical. Anolis sagrei have invaded Florida from Cuba, where close

525 relatives of $A$. carolinensis exhibit a similar ecomorphology to A. carolinensis (15). Spoil island

526 A. carolinensis, on the other hand, are being exposed to A. sagrei for the first time, and therefore

527 have the potential to be affected more strongly, as they have not already evolved to interact with

528 A. sagrei.

529

530

531 We captured lizards with noose poles and returned captured lizards to our field

532 laboratory. For every adult lizard caught, we measured toepad area and lamella number from

533 flatbed digital scans ( $2400 \mathrm{dpi}$ ) of the fourth toe of each hind foot. This toe is commonly used in

534 studies of Anolis toepad functional morphology, so we measured it in our study to maximize the

535 comparability of our data to that obtained in other research; however, we also note that lamellae

536 measures from different toes are significantly correlated in A. carolinensis (18). Specifically,

537 Glossip and Losos (18) counted lamellae on toes 2-5 on the fore- and hindfeet of 42 male and 24

538 female A. carolinensis. They found that males have more lamellae on each toe than females

539 (mean difference $=1.2 ; t$-test $>2.74, p<0.01$ in all cases), which is consistent with the sex effect

540 in our data (see below). Glossip and Losos also found that for males, 25 of 28 pairwise

541 comparisons showed significant correlations between lamella number on different toes (hindfoot

542 toe 2 vs. hindfoot toe 4 and hindfoot toe 5 versus hindfeet toes 3 and 4 being the exceptions).

543 Fifteen of 28 pairwise comparisons for females showed significant correlations for lamella 
544 number among toes; specific non-significant comparisons for females were not reported but the 545 authors noted "no pattern of which comparisons are significant and which are not" (18).

546 We measured lamella number by counting all lamellae on the third and fourth phalanges

547 of the toe and traced the area encompassed by those lamellae to measure toepad area. We

548 measured both traits for right and left toes and averaged sides for each trait for analysis. We also 549 measured snout-to-vent length (svl) using calipers, as a proxy for body-size used for correction

550 during analysis. Captured lizards were released at site of capture following measurement. To

551 prevent repeated measures of the same individual, lizards were marked with temporary ink and

552 permanent subcutaneous VI Alpha Tags (Northwest Marine Technologies) prior to release.

553 Sample sizes are in Table S3.

554 As above, we used linear mixed models to nest island random effects within our $A$.

555 sagrei-presence fixed effect. For toepad area and lamella number, separately, we built full 556 models that included lizard sex and svl as random effects: lme(trait $\sim$ sagrei presence*sex*svl, 557 random $=\sim \operatorname{sex}+\mathrm{svl} \mid$ island), where trait is either toepad area or lamella number. Neither the

558 three-way interaction term nor any of the two way interaction terms were significant so we chose 559 a reduced model that did not include interaction terms: lme(trait $\sim$ sagrei presence + sex + svl, 560 random $=\sim \operatorname{sex}+$ svl $\mid$ island). Residuals from this model were normally distributed for both 561 traits.

562 The presence of A. sagrei was a significant predictor for both toepad area and lamella

563 number (see main text for statistics). Toepad area was also significantly predicted by sex $\left(\beta_{\text {male }}=\right.$

$5640.46, t_{551}=4.4$, one-tailed $\left.p<0.001\right)$ and $\operatorname{svl}\left(\beta_{\mathrm{svl}}=0.12, t_{551}=12.8\right.$, one-tailed $\left.p<0.001\right)$, as

565 was lamella number $\left(\beta_{\text {male }}=0.88, t_{551}=4.5\right.$, one-tailed $\left.p<0.001\right)$ and svl $\left(\beta_{\mathrm{svl}}=0.04, t_{551}=2.4\right.$,

566 one-tailed $p=0.008$ ). Some evidence suggests that scale number in lizards might be fixed at

567 hatching (37), suggesting that size correction for lamella number is unnecessary. We built a

568 model, as above, but without including svl as a main effect. Results were qualitatively

569 unchanged. The presence of $A$. sagrei remained a significant predictor for lamella number

$570 \quad\left(\beta_{\text {invaded island }}=0.53, t_{9}=3.0\right.$, one-tailed $\left.p=0.002\right)$ as did sex $\left(\beta_{\text {male }}=1.27, t_{547}=13.4\right.$, one-tailed $571 p<0.001)$.

572

573 Rates of Divergence 
We calculated the mean rate of divergence for toepad area and lamella number using the

575 haldane (h), a measure of the proportional change per generation in standard deviation units (21).

576 This method assumes that the two populations (or sets of populations) are diverging from a

577 similar ancestral state. We used the equation

$$
h=\left(\left(x_{s} / s_{p}\right)-\left(x_{a} / s_{p}\right)\right) / g .
$$

$579 x$ is the mean of island trait-means for either size-corrected toepad area or size-corrected lamella 580 number. Subscript $s$ represents islands where A. carolinensis is sympatric with $A$. sagrei (i.e.,

581 invaded islands) while subscript $a$ represents islands where $A$. carolinensis is allopatric to $A$.

582 sagrei (i.e., un-invaded islands). $g$ is the number of generations since divergence began, which

583 we conservatively take to be 20 generations as A. carolinensis likely has slightly more than one

584 generation per year and A. sagrei began colonizing the islands during or after 1995. $s_{p}$ is the

585 pooled standard deviation of the island means across $a$ and $s$ islands; this value was calculated as

586 the square root of the within mean-squared error taken from a linear regression of size-corrected

587 trait mean against $A$. sagrei presence or absence. $p$-values were calculated using a randomization

588 test, whereby $a$ and $s$ were assigned to island means in every possible permutation and $h$ was

589 recalculated in each case to provide a distribution of $h$ values. We compared our observed $h$

590 values to this distribution. $\mathrm{R}$ scripts are available from the authors.

In late July 2011, we collected gravid A. carolinensis females from four invaded and four

594 un-invaded islands. We returned these gravid females to common cage conditions in an

595 environmentally controlled room within the University of Massachusetts Boston animal care

596 facility. Females were housed individually in Critter Keepers with bamboo dowels, cage carpet,

597 and a potted plant for laying eggs. Cages were illuminated with full-spectrum lighting. Lizards

598 were misted twice daily and fed 2-3 times per week with crickets that had been fed Flukers

599 Orange Cubes and Flukers High Calcium Cricket Diet. Directly before feeding to lizards,

600 crickets were also dusted with vitamin and calcium powders.

601 We checked plant pots for eggs three times per week from August-November 2011. We

602 collected, incubated, and hatched all laid eggs. We raised the offspring in individual cages and

603 shuffled cages regularly to randomize any within room environmental variation. Offspring were 
604 fed and misted by the same regimen as adults, except that smaller cricket sizes were used as 605 appropriate to the size of the lizard.

606 We raised the offspring for six months and then measured toepad area and lamella

607 number, as described above. Because of low sample sizes (Table S4), we did not differentiate by

608 sex in our models as our field data demonstrate significant effects of the presence of $A$. sagrei

609 regardless of whether sex is included in the model. We did not include an indicator for each

610 hatchling's dam, as there were no differences among dams from invaded and un-invaded islands

611 in svl, mass, or body condition (mass/svl) (Linear Mixed Models. svl: $\beta_{\text {sagrei present }}=-0.13, t_{6}=$ -

$6120.19, p=0.86$; mass: $\beta_{\text {sagrei present }}=0.11, t_{6}=1.07, p=0.33$; body condition: $\beta_{\text {sagrei present }}=0.002$, $\left.613 t_{6}=1.34, p=0.23\right)$.

$614 \quad$ For toepad area and lamella number, individually, we built a full model that included

615 lizard svl as a random effect: 1 me(trait $\sim$ sagrei presence*svl, random $=\sim$ svl $\mid$ island $)$. The

616 interaction term was not significant so we chose the following reduced model: lme(trait $\sim$ sagrei

617 presence + svl, random $=\sim$ svl $\mid$ island). Juvenile svl was not a significant predictor of lamella

618 number in this model $\left(\beta_{\mathrm{svl}}=0.07, t_{41}=1.4\right.$, one-tailed $\left.p=0.09\right)$.

Population genetics

621 To test the hypothesis that the observed evolutionary changes in multiple invaded islands 622 are independent, we assessed genetic relationships among the study populations of $A$.

623 carolinensis with genomic data. We used restriction-site associated DNA sequencing (RADseq)

624 to discover and genotype a large number of single-nucleotide polymorphism (SNP) loci across

625 individuals from nine study islands (Table S5). Following established protocols (38), we created

626 libraries for sequencing from 384 individuals. We used unique 6bp barcodes to multiplex 192

627 samples in each of two lanes of 100bp single-end sequencing on an Illumina HiSeq machine (U. 628 Oregon).

629 We obtained just over 404 million sequence reads. We de-multiplexed raw reads and

630 filtered for the presence of a correct barcode and restriction site using Stacks (39), leaving 314.8

631 million reads. We then aligned raw reads against the $A$. carolinensis reference genome (version

632 2.0.75) using Bowtie2 (40), discarding reads that aligned to more than one location in the

633 reference. We called diploid genotypes using a maximum likelihood model (as described by

$634[(39,41)]$, implemented using code available at 
$635 \mathrm{http} / /$ webpages.uidaho.edu/hohenlohe/software.html, with a Phred quality score minimum of 10 636 and prior bounds on the nucleotide error rate of 0.001 and 0.1 . Genotypes were called at 161,038 637 RAD tag loci. From these genotypes we identified single-nucleotide polymorphisms (SNPs) 638 across the complete set of individuals. We removed 5 individuals for low numbers of called 639 genotypes (i.e., low coverage), and we removed any putative SNPs genotyped in fewer than 150 640 individuals, with minor allele frequency less than 0.05 across the combined sample set, or with 641 more than two alleles. This analysis and filtering produced a final dataset of 121,973 biallelic 642 SNPs genotyped across 379 individuals.

643 We assessed genetic clustering of individuals based on this set of SNPs with a neighbor644 joining phylogenetic network using SplitsTree4 version 4.13.1 (42), by using custom scripts to 645 convert genotypes at the 121,973 SNPs to nexus format. We used default settings for 646 SplitsTree4, which estimates uncorrected Hamming distance between individuals based on 647 diploid genotypes and generates a phylogenetic network with the NeighborNet algorithm (43).

648 We found island populations to be well-defined. There is no indication of clustering of islands by 649 invasion status, and the few individuals that do not cluster with their home island population 650 show no sign of preferential migration among islands of similar invasion status (Figure 4).

651 We also calculated the genome-wide average pairwise $F_{\mathrm{ST}}$ using the variance

652 decomposition method of (44) among all islands from the set of 121,973 SNPs (code available at $653 \mathrm{http} / /$ webpages.uidaho.edu/hohenlohe/software.html). We assessed grouping of islands based on 654 the pairwise $F_{\mathrm{ST}}$ matrix (Table S6) with several approaches: principal coordinates analysis using 655 the $\mathrm{R}$ function $\mathrm{cmdscale()}$ with varying levels of the number of dimensions $k$; neighbor-joining 656 trees using the R package APE (45); and the NeighborNet algorithm in SplitsTree4. None of 657 these suggested any relationship between invasion status and genetic grouping of populations. 658 We also tested for a difference in mean $F_{\mathrm{ST}}$ depending on similarity or difference in invasion 659 status with a 2-sample t-test using the $\mathrm{R}$ function $t$.test(), which was not significant $(p>0.5)$. We 660 tested for isolation by distance using a Mantel test [R function mantel.test()] to compare matrices 661 of pairwise $F_{\mathrm{ST}}$ and geographic distance (Table S6) and found no relationship ( $p>0.25$ ).

\section{Full Acknowledgments:}

664 We thank A. Kamath, C. Gilman, A. Algar, J. Allen, J. Archer, E. Boates, A. Echternacht, F. 665 Gregg, A. Harrison, J. Kolbe, H. Lyons-Galante, J. McCrae, J. Newman, R. Pringle, J. Rifkin, M. 
666 Stimola, P. VanMiddlesworth, K. Winchell, and K. Wollenberg for assistance; A. Algar and A. 667 Kamath for photographs; T. Max and C. Wiench for preparing RADseq libraries; three 668 anonymous reviewers for helpful comments and improvements; M. Legare and J. Lyon from 669 Merritt Island National Wildlife Refuge and J. Stiner and C. Carter from Canaveral National 670 Seashore for permission to conduct this research; Harvard University, Museum of Comparative 671 Zoology, University of Massachusetts Boston, University of Tennessee Knoxville, University of 672 Tampa, NSF (DEB-1110521) and NIH (P30GM103324) for funding.

673 


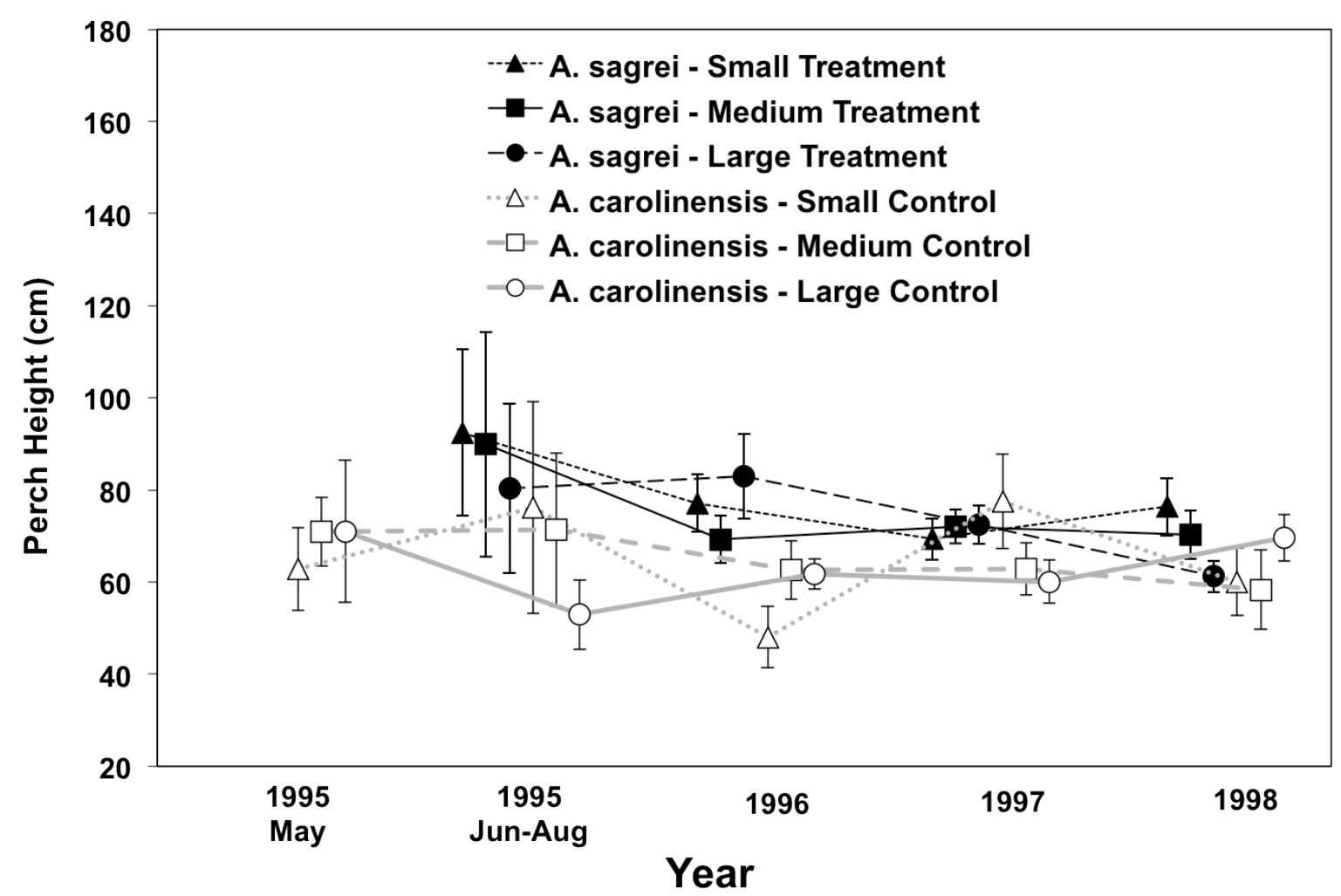

674

675 Fig. S1 Perch height through time during the 1995-1998 introduction experiment for A. sagrei

676 (filled shapes) on treatment islands and allopatric $A$. carolinensis (open shapes) on control

677 islands. Island means ( \pm 1 s.e.) are shown for each island. 


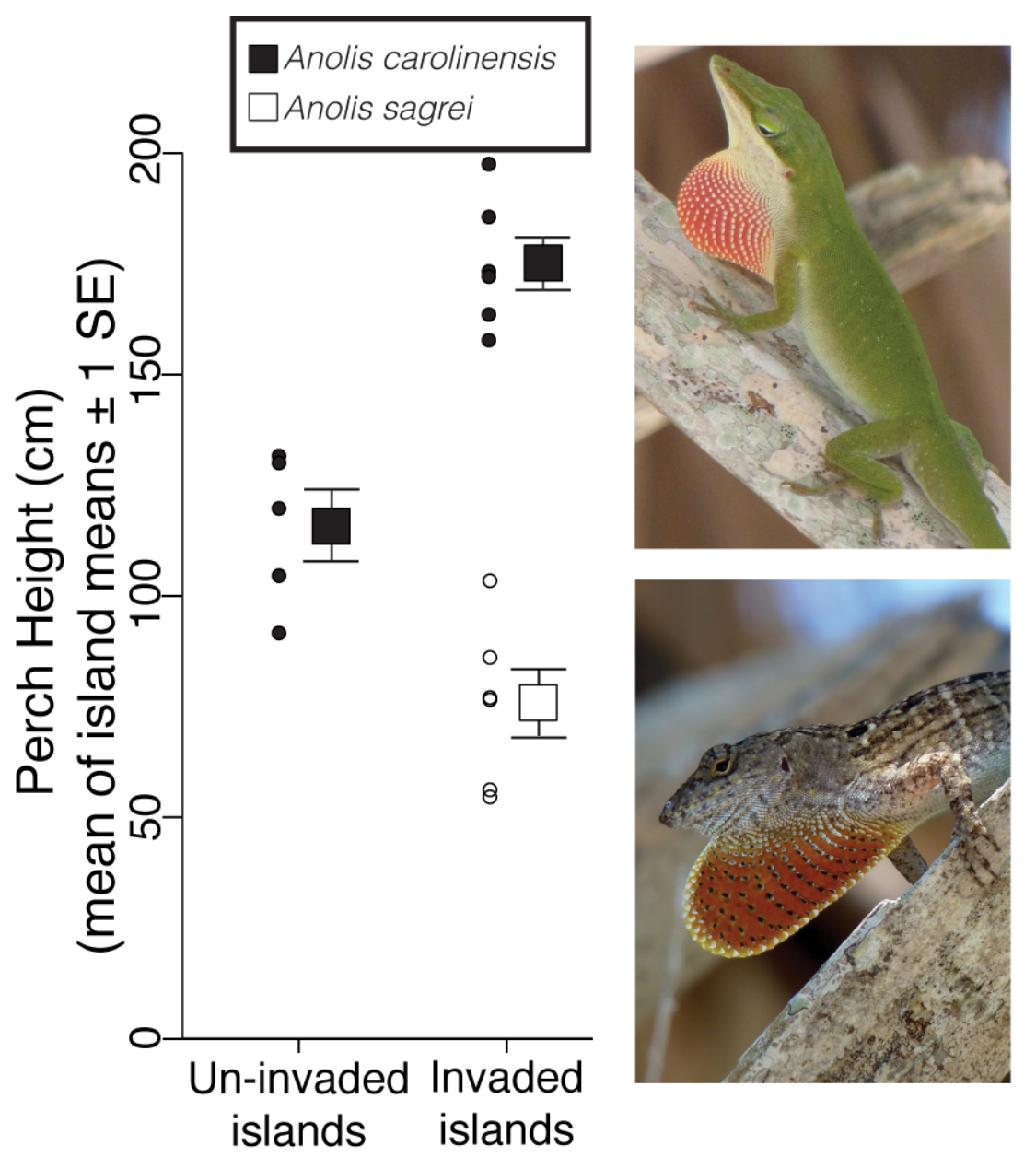

680 Fig. S2. Habitat use shift by $A$. carolinensis in the 2010 toepad study. Mean of island means $( \pm 1$ 681 s.e.) for perch height by $A$. carolinensis (closed squares) on un-invaded $(\mathrm{n}=5)$ and invaded 682 islands $(\mathrm{n}=6)$. The invasion of $A$. sagrei corresponds with a significant increase in perch height 683 by $A$. carolinensis (Linear Mixed Model: $\beta_{\text {invaded island }}=2.77, t_{9}=6.6$, one-tailed $p<0.001$; island 684 sample sizes 57-110). Perch height of A. sagrei shown for comparison (open square; $\mathrm{n}=6$ ).

685 Mean perch heights for each island for A. carolinensis (small, closed circles) and A. sagrei 686 (small, open circles) are shown also. Top right: Anolis carolinensis. Bottom right: Anolis sagrei. 687 
688 Table S1. Sample sizes for A. carolinensis and A. sagrei perch heights by island in the 19956891998 introduction experiment.

\begin{tabular}{lccccccc} 
Island & Size & Type & $\begin{array}{c}1995 \text { Pre- } \\
\text { Introduction }\end{array}$ & $\begin{array}{c}1995 \text { Post- } \\
\text { Introduction }\end{array}$ & 1996 & 1997 & 1998 \\
\hline Zero & Small & Treatment & 40 & 45 & 54 & 47 & 17 \\
Ant & Medium & Treatment & 64 & 26 & 88 & 15 & 11 \\
Yin $^{\mathrm{b}}$ & Large & Treatment & 56 & 30 & 89 & 68 & 54 \\
Fellers & Small & Control & 22 & 9 & 34 & 27 & 32 \\
Tarp & Medium & Control & 45 & 23 & 84 & 78 & 41 \\
Lizard & Large & Control & 18 & 45 & 213 & 146 & 121 \\
\hline \multirow{2}{*}{ Zero } & Small & Treatment & n/a & $23^{\mathrm{a}}$ & 89 & 157 & 140 \\
Ant & Medium & Treatment & n/a & $10^{\mathrm{a}}$ & 97 & 289 & 144 \\
Yin & Large & Treatment & n/a & $4^{\mathrm{a}}$ & 41 & 218 & 291 \\
\hline
\end{tabular}

$690{ }^{a}$ The number of first-captures of introduced individuals

691 b Yin (LT) and Lizard (LC) were included as "invaded" islands in the 2010 toepad study. 
693 Table S2. Perch height analysis for the1995-1998 A. sagrei introduction experiment. Mixed 694 model output is shown for a datasets (A) including and (B) excluding pre-introduction perch 695 height data (12).

\begin{tabular}{|c|c|c|c|c|c|}
\hline & $\begin{array}{l}\beta \\
\text { Coefficient }\end{array}$ & $\begin{array}{l}\text { Standard } \\
\text { Error }\end{array}$ & $\begin{array}{l}\text { Degrees of } \\
\text { Freedom }\end{array}$ & $t$-value & $\begin{array}{l}2 \text {-sided } p \text { - } \\
\text { value }\end{array}$ \\
\hline Intercept $^{\mathrm{a}}$ & 6.28 & 0.41 & 1627 & 17.18 & 0.000 \\
\hline Treatment $^{\mathrm{b}}$ & 0.50 & 0.49 & 4 & 1.02 & 0.365 \\
\hline $1995^{\mathrm{c}}$ & -0.47 & 0.58 & 1627 & -0.81 & 0.418 \\
\hline 1996 & -0.37 & 0.45 & 1627 & -0.83 & 0.405 \\
\hline 1997 & -0.23 & 0.46 & 1627 & -0.51 & 0.607 \\
\hline 1998 & -0.04 & 0.47 & 1627 & -0.09 & 0.925 \\
\hline $\operatorname{Sex}^{\mathrm{d}}$ & 1.85 & 0.18 & 1627 & 10.12 & 0.000 \\
\hline Treatment* $1995^{\mathrm{e}}$ & 2.48 & 0.74 & 1627 & 3.34 & 0.001 \\
\hline Treatment*1996 & 2.09 & 0.59 & 1627 & 3.57 & 0.000 \\
\hline Treatment*1997 & 2.34 & 0.63 & 1627 & 3.70 & 0.000 \\
\hline Treatment*1998 & 3.48 & 0.69 & 1627 & 5.03 & 0.000 \\
\hline
\end{tabular}

B) Excludes pre-introduction (May 1995) perch height data from treatment and control islands.

\begin{tabular}{llllll} 
& $\beta$ & $\begin{array}{l}\text { Standard } \\
\text { Coefficient }\end{array}$ & $\begin{array}{l}\text { Degrees of } \\
\text { Erroedom }\end{array}$ & $t$-value & $\begin{array}{l}\text { 2-sided } p \text { - } \\
\text { value }\end{array}$ \\
\hline Intercept $^{\mathrm{a}}$ & 5.76 & 0.43 & 1384 & 13.54 & 0.000 \\
Treatment $^{\mathrm{b}}$ & 2.98 & 0.55 & 4 & 5.45 & 0.006 \\
1996 & 0.09 & 0.46 & 1384 & 0.21 & 0.837 \\
1997 & 0.23 & 0.47 & 1384 & 0.48 & 0.628 \\
1998 & 0.42 & 0.49 & 1384 & 0.86 & 0.392 \\
Sex $^{\mathrm{d}}$ & 1.95 & 0.20 & 1384 & 9.99 & 0.000 \\
Treatment*1996 & -0.39 & 0.63 & 1384 & -0.62 & 0.533 \\
Treatment*1997 & -0.13 & 0.67 & 1384 & -0.19 & 0.846 \\
Treatment*1999 & 0.99 & 0.73 & 1384 & 1.36 & 0.175 \\
\hline
\end{tabular}

$696{ }^{\mathrm{a}}$ The intercept represents control islands at first collection (A: May 1995; B: June-August 1995).

$697{ }^{\mathrm{b}}$ Treatment represents the effect of introduction on perch height, compared to controls.

698 c 1995 June-August, post-introduction.

$699{ }^{\mathrm{d}}$ The sex coefficient represent the effect of being male on perch heights, compared to females.

$700{ }^{\mathrm{e}}$ This is the interaction between treatment and June-August 1995, post-introduction. 
701 Table S3. Anolis sagrei invasion status, A. carolinensis perch height sample size, and $A$.

702 carolinensis morphology sample size by island for the 2010 toepad study. For sample sizes, 703 males are listed before the "" and females after. Yin and Lizard were the LT and LC islands,

704 respectively, in the 1995-1998 introduction experiment. For reference, in Fig. 2, from north to 705 south, the study islands (circles) are Lizard, Hook, Yin, Yang, Hornet, Crescent, Pine, North 706 Twin, South Twin, Channel, and Osprey.

707

\begin{tabular}{lccc} 
Island & $\begin{array}{c}\text { A. sagrei } \\
\text { invasion }\end{array}$ & $\begin{array}{c}\text { Perch height } \\
\text { sample size (M/F) }\end{array}$ & $\begin{array}{c}\text { Morphology sample } \\
\text { size (M/F) }\end{array}$ \\
\hline Channel & Yes & $51 / 15$ & $38 / 15$ \\
Crescent & No & $50 / 12$ & $38 / 10$ \\
Hook & Yes & $53 / 22$ & $42 / 16$ \\
Hornet & No & $60 / 27$ & $44 / 15$ \\
Lizard $^{\text {a }}$ & Yes & $70 / 40$ & $41 / 19$ \\
North Twin & Yes & $49 / 21$ & $33 / 11$ \\
Osprey & No & $52 / 15$ & $33 / 10$ \\
Pine & No & $38 / 19$ & $27 / 14$ \\
South Twin & No & $60 / 38$ & $34 / 24$ \\
Yang & Yes & $57 / 14$ & $41 / 16$ \\
Yin & Yes & $48 / 12$ & $27 / 16$ \\
\hline
\end{tabular}

${ }^{\text {a }}$ The large control (LC) island in the 1995-1998 study.

$709{ }^{\mathrm{b}}$ The large treatment (LT) island in the 1995-1998 study. 
712 Table S4. Anolis sagrei invasion status, dam and hatchling sample size by island for the

713 common garden experiment in the 2010 toepad study. For the column describing hatchlings per

714 female, the numbers separated by colons denote how many hatchlings were reared to

715 measurement per female.

716

\begin{tabular}{lcccc} 
Island & $\begin{array}{c}\text { A. sagrei } \\
\text { invasion }\end{array}$ & $\begin{array}{c}\text { Dam sample } \\
\text { size }\end{array}$ & $\begin{array}{c}\text { Hatchling } \\
\text { sample size }\end{array}$ & $\begin{array}{c}\text { Hatchlings per } \\
\text { female }\end{array}$ \\
\hline Hornet & No & 3 & 6 & $1: 2: 3$ \\
Lizard & Yes & 6 & 12 & $1: 1: 1: 2: 3: 4$ \\
North Twin & Yes & 8 & 10 & $1: 1: 1: 1: 1: 1: 2: 2$ \\
Osprey & No & 5 & 8 & $1: 1: 1: 2: 3$ \\
Pine & No & 1 & 2 & 2 \\
South Twin & No & 5 & 7 & $1: 1: 1: 2: 2$ \\
Yang & Yes & 6 & 10 & $1: 1: 1: 2: 2: 3$ \\
Yin & Yes & 5 & 6 & $1: 1: 1: 1: 2$
\end{tabular}

717

718 
719 Table S5. RADseq summary statistics for the 2010 toepad study. $n$ is number of individuals, 720 with the number after filtering for low coverage in parentheses. Number of SNPs is the mean 721 number genotyped per individual within each population, after filtering to a total of 121,973 722 SNPs.

723

\begin{tabular}{lccc}
\multicolumn{1}{c}{ Island } & $\begin{array}{c}\text { A. sagrei } \\
\text { invasion }\end{array}$ & $n$ & \# SNPs genotyped \\
\hline Channel & Yes & 14 & $80,909.5$ \\
Hook & Yes & 48 & $71,930.2$ \\
Hornet & No & 48 & $96,405.3$ \\
Lizard & Yes & $48(46)$ & $40,262.1$ \\
North Twin & Yes & $46(45)$ & $15,628.0$ \\
Osprey & No & 42 & $81,783.3$ \\
Pine & No & 43 & $89,439.1$ \\
South Twin & No & $47(46)$ & $94,641.3$ \\
Yang & Yes & $48(47)$ & $94,794.1$ \\
Total & & $384(379)$ & $74,524.4$
\end{tabular}


726 Table S6. Pairwise $F_{\text {ST }}$ between islands estimated from 121,973 SNP loci above the diagonal, 727 and geographic distance between island centers in meters below the diagonal. Invaded islands: 728 Hook, Channel, Lizard, North Twin, Yang. Un-invaded islands: Hornet, Osprey, Pine, South 729 Twin.

$\begin{array}{lccccccccc} & & & & & & & \text { North } & \text { South } \\ & \text { Hook } & \text { Hornet } & \text { Osprey } & \text { Pine } & \text { Channel } & \text { Lizard } & \text { Twin } & \text { Twin } & \text { Yang } \\ \text { Hook } & - & 0.15 & 0.14 & 0.14 & 0.12 & 0.12 & 0.13 & 0.14 & 0.14 \\ \text { Hornet } & 1360 & - & 0.16 & 0.16 & 0.15 & 0.14 & 0.15 & 0.15 & 0.16 \\ \text { Osprey } & 12085 & 10726 & - & 0.16 & 0.14 & 0.13 & 0.15 & 0.15 & 0.16 \\ \text { Pine } & 4102 & 2742 & 7984 & - & 0.14 & 0.14 & 0.15 & 0.15 & 0.15 \\ \text { Channel } & 6659 & 5299 & 5428 & 2557 & - & 0.11 & 0.13 & 0.134 & 0.14 \\ \text { Lizard } & 499 & 1858 & 12584 & 4600 & 7157 & - & 0.11 & 0.13 & 0.14 \\ \text { North Twin } & 4471 & 3111 & 7615 & 370 & 2188 & 4969 & - & 0.09 & 0.15 \\ \text { South Twin } & 4758 & 3399 & 7328 & 656 & 1901 & 5256 & 288 & - & 0.15 \\ \text { Yang } & 482 & 879 & 11604 & 3620 & 6177 & 980 & 3989 & 4276 & - \\ \text { T30 } & & & & & & & & & \end{array}$


733 Table S7. Tests for environmental heterogeneity between un-invaded $(n=5)$ and invaded $(n=6)$

734 islands in the 2010 toepad study. Invasion status was treated as a binary variable and we used

735 logistic regression to test whether the environmental variable could predict invasion status.

736

\begin{tabular}{lcccc} 
Variable & $\beta$ & Standard Error & Z-value & $\begin{array}{c}\text { p-value (two- } \\
\text { sided) }\end{array}$ \\
& & & & 0.44 \\
\hline Distance to Shore $(\mathrm{m})$ & 0.006 & 0.007 & 0.770 & 0.34 \\
Island Area $\left(\mathrm{m}^{2}\right)$ & 0.0002 & 0.0002 & 0.115 & 0.908 \\
Vegetated Area $\left(\mathrm{m}^{2}\right)$ & 0.00001 & 0.00001 & -0.275 & 0.784 \\
Available Tree Heights & 0.282 & 1.03 & & \\
(cm) & & & 0.775 & 0.450 \\
Shannon Diversity & 4.99 & 6.61 & & \\
Index & & & 0.822 & 0.411 \\
Simpson Diversity & 18.33 & 22.29 & & \\
Index & & &
\end{tabular}

